\title{
A comprehensive strategy to avoid trans- esophageal echocardiography probe damage
}

\author{
[Une stratégie détaillée pour éviter les dommages à la sonde d'échocardiographie \\ transesophagienne]
}

Jean Taillefer MD FRCPC, Pierre Couture MD FRCPC, Peter Sheridan MD FRCPC, Alain Girard, Denis Babin MSc, André Denault MD FRCPC

Purpose: To describe the factors predisposing to transesophageal echocardiography (TEE) probe damage and to propose a strategy aimed at preventing damage to the TEE probe.

Description of equipment and procedures: Damage to the TEE probe can occur anywhere and anytime during use in the operating room (OR) or when the probe is not in use in the OR, such as in the cleaning room, during storage or during transport of the probe. The components of the strategy used in our institution to avoid probe damage are: I) storage of the probe in a dedicated holder in the OR when it is not in use, 2) use of a lexan box in the OR to protect the probe connector, 3) use of a custom-made holder when the probe is inserted in the patient, 4) use of a dedicated holder for soiled TEE probe storage in the cleaning room and for subsequent probe storage.

Conclusion: We describe a comprehensive strategy designed to decrease TEE probe damage and the associated expenses. Further studies will be required to determine the effectiveness of the proposed measures.

Objectif : Décrire les facteurs prédisposant à des altérations de la sonde d'échocardiographie transœsophagienne (ETO) et proposer une stratégie qui vise à les prévenir.

Matériel et méthode : Des dommages peuvent être causés à la sonde d'ETO n'importe où et n'importe quand pendant son utilisation en salle d'opération (SO) ou ailleurs, par exemple lors du nettoyage, de l'entreposage ou du transport. Les composantes de la stratégie utilisée à notre hôpital sont: I) l'entreposage de la sonde sur un support réservé dans la SO quand on ne s'en sert pas, 2) l'utilisation d'une boîte en lexan dans la SO pour protéger le connecteur de la sonde, 3) l'utilisation d'un support personnalisé au moment de l'insertion de la sonde chez le patient, 4) l'usage d'un support spécifique pour le rangement des sondes d'ETO souillées dans la salle de nettoyage et pour l'entreposage subséquent.
Conclusion : Nous avons décrit une stratégie détaillée conçue pour diminuer les altérations de la sonde d'ETO et les dépenses associées. Il reste à déterminer l'efficacité des mesures proposées.

\section{Purpose}

Transesophageal echocardiography (TEE) is increasingly used during cardiac surgery and has been shown to have a significant clinical impact. ${ }^{1}$ However, the TEE probe and machine are expensive and were not designed primarily for use in the operating room (OR). In the echography laboratory, the probe is only inserted in the patient for the duration of the study (generally $<20 \mathrm{~min}$ ) and, consequently, is under the direct care of the echocardiographer while in clinical use. This is usually not the case in the OR.

Numerous risk factors for TEE probe damage are almost uniquely encountered in the OR. For intraoperative use, the TEE probe is usually placed after anesthetic induction and stays in place for a prolonged period of time, typically from three to five hours. In our institution, four OR's share four probes and two echocardiography machines. Consequently, the TEE probe is frequently disconnected from the machine, exposing the probe to damage from exposure to liquids, impacts and falls to the floor. In a crowded and busy environment such as the OR, where many health professionals (anesthesiologists, residents, respiratory therapists) work in a limited space near the head of the patient, dropping or mishandling of the probe may occur and result in damage to the probe, connector, or

From the Department of Anesthesiology, Montreal Heart Institute, Montreal, Quebec, Canada.

Address correspondence to: Dr. André Denault, Department of Anesthesiology, Montreal Heart Institute, 5000 Bélanger Street East,

Montreal, Quebec HIT 1C8, Canada. Phone: 514-376-3330, ext. 3732; Fax: 514-376-8784; E-mail: denault@videotron.ca Accepted for publication November 20, 2001.

Revision accepted February 2, 2002. 


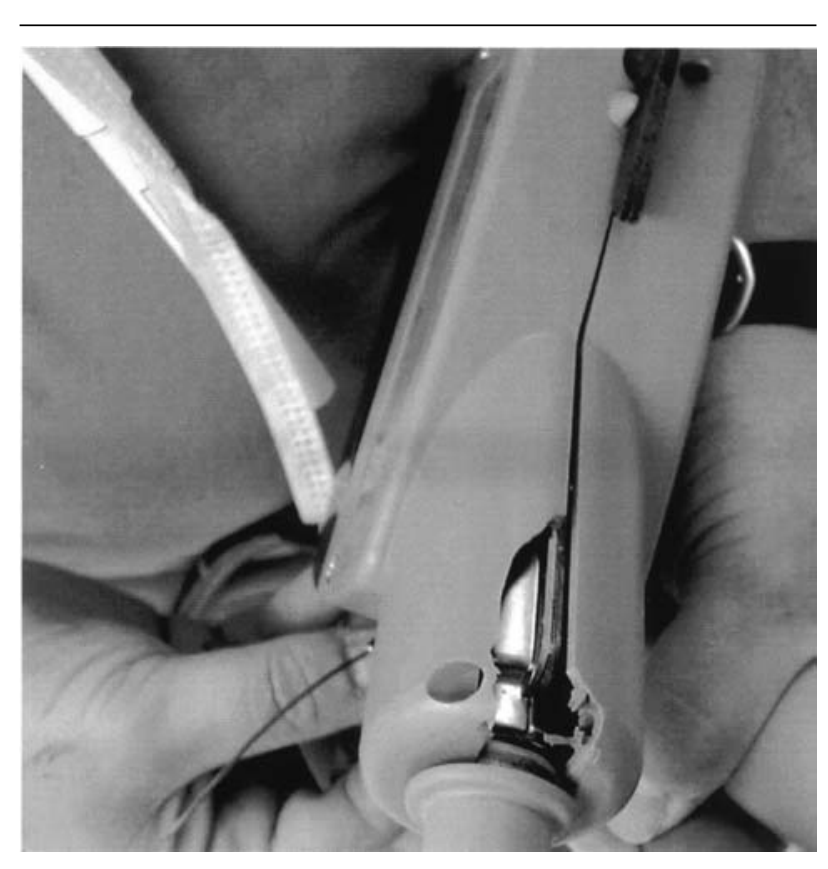

FIGURE 1 Broken transesophageal echocardiography probe connector.

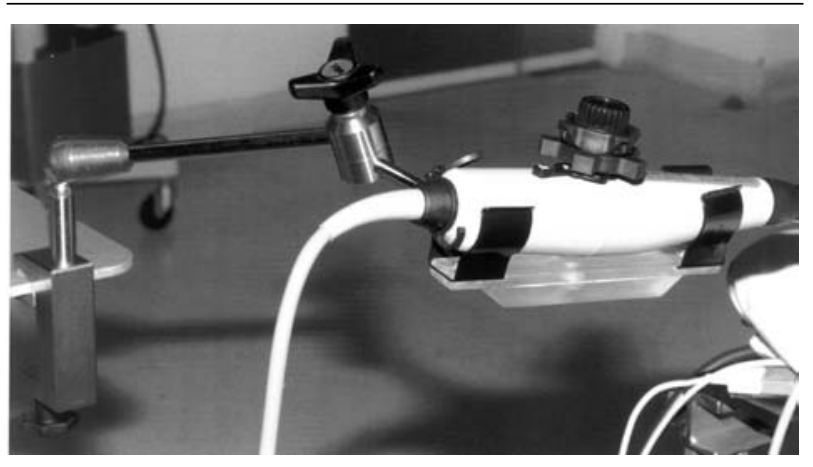

FIGURE 2 Transesophageal echocardiography probe holder for intraoperative use.

the control housing. Kinking of the probe shaft near the control housing for prolonged periods can lead to probe malfunction. In contrast to the echography laboratory where TEE probes are cleaned on site, the probe is transported to a remote location, and damage can occur during transport or while the probe is not in use, either before cleaning or before reuse in the OR. The resulting repairs are expensive and can take the probe out of service for a prolonged period. The cost for reconditioning a multiplane TEE probe (Sonos 5500, Hewlett-Packard, Andover, MA, USA) is close to $\$ 27,000 \mathrm{CAN}$, and the cost of a casing is $\$ 40.00 \mathrm{CAN}$.

\section{Description of equipment and procedures}

After a Medline search, we identified four letters to the Editor in the English anesthesia literature describing devices used for holding the handle of the TEE probe in the OR. ${ }^{2-5}$ However, these do not prevent damage to the plastic casing of the probe connector, kinking at the junction of the handle and the probe shaft, or damage of the plastic casing caused during transport or storage of the probe when it is not in use (Figure 1). Considering the factors predisposing to probe damage mentioned above, we describe here each component of a global strategy aimed at preventing damage to the TEE probes used at our institution.

The device used for holding the control housing or handle, while the probe is inserted in the patient, is shown in Figure 2. The device is a modification of the arm used with a commercially available esophageal Doppler (Arrow Medical products, HAS-00100, Oakville, ON, Canada; www.arrowintl.com). The modification consists of a lexan plate, with PVC coated flashlight holder clips (Spaenaur, Kitchener, ON, Canada) attached to the arm. The flashlight clips serve as a cradle for the handle. The articulated arm is multiadjustable and can be attached to many structures, including an $i v$ pole, the rail of the operating table or a table edge. The total cost of the device is $\$ 1,200$ CAN. The arm can easily be manipulated and secured in place with one hand. Careful positioning of the device prevents kinking of the probe shaft at the handle. Furthermore, it can be used to hold the probe in order to maintain a specific monitoring view or allows the examiner to manipulate the shaft of the probe with one hand and the echo machine with the other. To protect the probe connector when it is not attached to the echo machine, we insert the connector into a lexan box, fixed on a column to the left of the operating table (Figure $3)$. During the transport of the probe before cleaning and during storage, we use the protector recommended by the manufacturer to protect the tip of the TEE probe (Tip protector for Omniplane TEE probe, HP M2243A, Hewlett Packard, Andover, MA, USA). The tip protector is brushed, cleaned and left with the TEE probe in glutaraldehyde $2 \%$ for $20 \mathrm{~min}$ according to the recommendations of our infectious disease department. Finally, when the TEE probes are not in use, we store them in probe holders. These probe holders (Figure 4) were installed in the cleaning room, in the OR, and in the storage room.

\section{Discussion}

Although TEE probe damage is a real problem which results in significant costs, few recommendations regarding TEE probe protection are available. Over a 


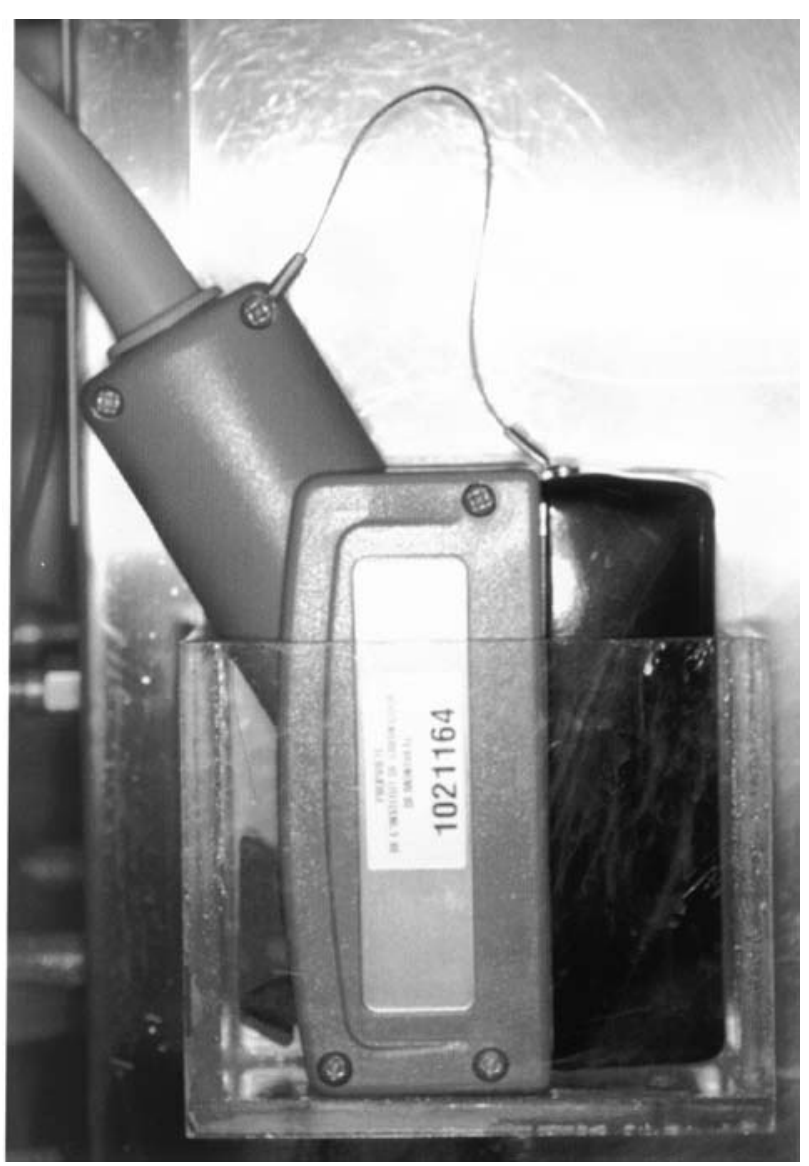

FIGURE 3 Protective lexan box for the probe connector.

single year, we have experienced damages to more than 20 casings and we had to recondition two TEE probes. In this report, we have described the strategy used in our institution and believe that its application will decrease the incidence of TEE probe damage. Further studies will be required to determine if this preventive approach can reduce the overall incidence of probe damage and the associated costs.

\section{Acknowledgements}

We are grateful to Jean Leclerc from the audio-visual Department and Diane Campeau for secretarial support.

\section{References}

1 Couture P, Denault AY, McKenty S, et al. Impact of routine use of intraoperative transesophageal echocardiography during cardiac surgery. Can J Anesth 2000; 47: 20-6.

2 Brooker RF. Transesophageal echocardiography probe holder (Letter). Anesth Analg 1994; 79: 810.

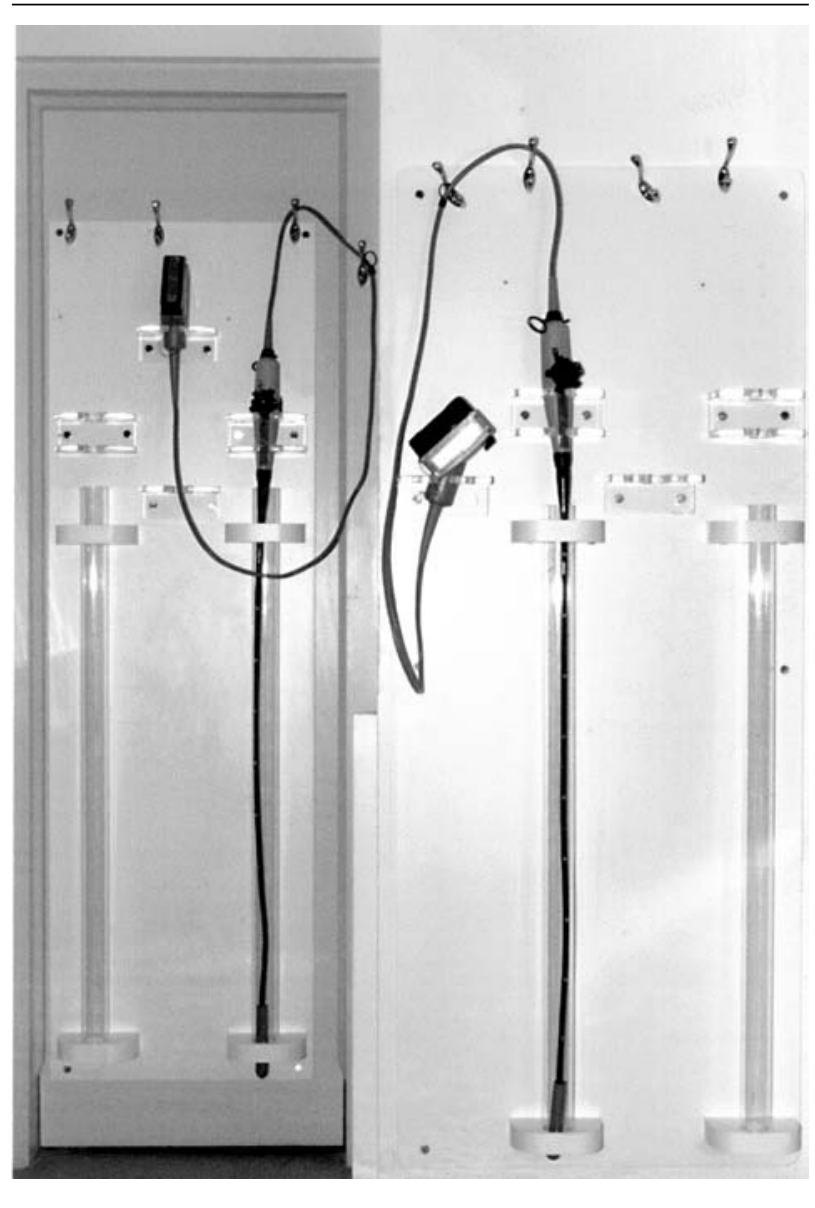

FIGURE 4 Probe holder for storage.

3 Spiess BD, Bruck DA. Transesophageal echocardiography probe holder (Letter). Anesth Analg 1997; 85: 945.

4 Michelsen LG. A more simple holder for the transesophageal echocardiography probe (Letter). Anesth Analg 1998; 86: 677.

5 Kainuma M, Miyake T. A convenient holder of the transesophageal echocardiography probe (Letter). Anesthesiology 2000; 93: 1564. 